\title{
Changes in Phytoplankton Biomass in the Western Scheldt Estuary During the Period 1978-2006
}

\author{
Jacco C. Kromkamp • Tom Van Engeland
}

Received: 23 September 2008 /Revised: 4 August 2009 / Accepted: 7 August 2009 / Published online: 27 August 2009

(C) The Author(s) 2009. This article is published with open access at Springerlink.com

\begin{abstract}
We investigated whether climate change results in long-term changes in phytoplankton biomass and phenology in a turbid eutrophic coastal plain estuary. Changes in annual mean chlorophyll $a(\operatorname{chl} a)$ concentrations were studied for the period 1978-2006 in the eutrophic and turbid macro-tidal Western Scheldt estuary. Three stations were investigated: WS1, at the mouth of the estuary; station WS6, halfway up the estuary; and station WS11, near the Dutch-Belgian border near the upstream end of the estuary. No significant long-term changes in yearly averaged chl $a$ concentrations were observed in WS1 and WS6, but in WS11 the phytoplankton biomass decreased considerably. This is most likely due to an increase in grazing pressure as a result of an improvement in the dissolved oxygen concentrations. Spectral analyses revealed a possible periodicity of 7 years in the mean chla which was related to periodicity in river discharge. We also observed strong phenological responses in the timing of the spring/summer bloom which were related to a welldocumented increase in the temperature in the estuary. The fulcrum, the center of gravity or the day at which $50 \%$ of the cumulative chla was reached during the year, advanced by 1-2 days/year. A similar trend was observed for the month in which the maximum bloom was observed, with the exception of station WS1. All stations showed an earlier initiation of the bloom, whereas the day at which the phytoplankton bloom was terminated also moved forward in time excepted for WS11. As a result, the bloom length decreased at station WS1, remained the same at station
\end{abstract}

J. C. Kromkamp $(\bowtie) \cdot$ T. Van Engeland

Netherlands Institute of Ecology,

Centre for Estuarine and Marine Ecology (NIOO-CEME),

PO Box 140, 4400 AC Yerseke, The Netherlands

e-mail: j.kromkamp@nioo.knaw.nl
WS6, and increased at WS11. This complicated pattern in bloom phenology demonstrates the complex nature of ecosystem functioning in estuaries.

Keywords Chlorophyll $a \cdot$ Times series · Phenology · Phytoplankton biomass · Western Scheldt estuary

\section{Introduction}

The influence of climate change is well documented in marine ecosystems. Regime shifts have been observed in many oceans and seas like the North Pacific (Chiba et al. 2008; Hare and Mantua 2000), the Atlantic (Beaugrand 2004a), the Baltic (Hakanson and Lindgren 2008), the North Sea (Edwards et al. 2002; McQuatters-Gollop et al. 2007; Weijerman et al. 2005), as well as in many lakes (Scheffer et al. 2001). These regime shifts are often driven by changes in large-scale weather patterns like the Pacific decadal oscillation or the North Atlantic Oscillation (NAO). Because of the semicyclic pattern of these changes, they might obscure changes induced by human-induced climate change. Climate-induced warming events are well documented as changes in phenology in terrestrial systems (Walther et al. 2002). Marine systems are less well documented, especially with regard to the lowest levels of the foodweb. Edwards and Richardson (2004) noticed a significant earlier start in the development of dinoflagellates and zooplankton in the North Sea, whereas the timing of diatom blooms in general did not change. The Helgoland Road (German Bight, North Sea) time series, with its high temporal resolution, also did exhibit a longterm change in the timing of the spring bloom, although the spring bloom seemed to be delayed in warm years (Wiltshire et al. 2008). 
Estuaries have been less well studied with respect to phenology and climate change. Because estuarine ecosystem function is heavily influenced by land-use changes, it might be very hard to actually detect signals due to climate change. Nevertheless, regime shifts have been observed in estuaries. In North San Francisco Bay, the introduction of the Asian clam (Potamocurbula amurensis) drastically reduced the magnitude of the phytoplankton blooms (Cloern 2001). Climate change causes migration of benthic marine species, but often, these sorts of introductions are caused by man with species migrating in ballast tanks of ships.

The heterotrophic Western Scheldt estuary is a turbid, well-mixed, macro-tidal eutrophic estuary. In the last two decades, the water quality of the estuary has improved considerably, due to gradually increased efforts since the end of the 1970s to treat wastewater before it is discharged into the Schelde River (Soetaert et al. 2006). Changes in nutrient concentrations have been recently summarized by Soetaert et al. (2006). In addition, there is regular dredging to remove sills in order to allow large ships to enter the port of Antwerp. Despite the large changes in nutrient loads and dredging activity, primary production does not seem to have changed significantly between 1991 and 2001 (Kromkamp and Peene 2005). This is probably due to the fact that even though phosphate concentrations might have reached potentially limiting concentrations for short periods in spring in the mouth of the estuary, it is the high turbidity that is still mainly causing light-limited growth of the phytoplankton.

The objective of this paper was to determine if longterm changes in phytoplankton biomass and the timing of the phytoplankton bloom in this heavily anthropogenically influenced estuary occur as a result of climate change. We observed complex changes in the phenology of the bloom initiation and bloom termination during the period 1978-2006.

\section{Materials and Methods}

\section{Study Site}

The Western Scheldt estuary, situated in the border region of Belgium and the Netherlands, is shown in Fig. 1. Salinity intrudes for about $100 \mathrm{~km}$ inland, and the freshwater tidal zone reaches another $50 \mathrm{~km}$ upstream. The estuary has a relatively long water residence time of 50-70 days (Soetaert and Herman 1995). The catchment area of the Scheldt estuary is mainly urban, but it has densely populated areas and is heavily industrialized with more than 10 million people living in it. It covers $21,863 \mathrm{~km}^{2}$ and includes the northwest of France (31\%), the west of Belgium (61\%), and the southwest of the Netherlands (8\%) (Soetaert et al. 2006). The Western Scheldt estuary is the entrance to the port of Antwerp, the second largest port in Western Europe. A maximum turbidity zone is usually situated between a salinity of 2 and 10 . The estuary is macro-tidal, and as a result, it is very turbid and well mixed (Kromkamp and Peene 1995b; Soetaert et al. 2006). Despite the fact that a decrease in nutrient load improved the water quality, phytoplankton are still most likely light-limited throughout the estuary (Kromkamp and Peene 2005; Soetaert et al. 2006). This can also be seen from the shallow Secchi depths (Fig. 2). Some nutrient data are presented for stations WS1 and WS11, the end members of the study period 1978-1980 and for 2004-2006. These data clearly show that nutrient concentrations upstream are still very high despite a decrease in especially phosphate and to a lesser degree dissolved inorganic nitrogen. Phosphate concentrations in the mouth of estuary (station WS1) are low for a short period in spring. All other nutrients are in excess. For a comprehensive overview about changes in nutrient concentration in the Schelde estuary, see Soetaert et al. (2006).

The estuary is sampled for monitoring by the Netherlands Institute of Coastal and Marine Management (RIKZ), which has four sites in the estuary: Vlissingen (Flushing, WS1), a station in the mouth of the estuary with an average salinity of $\sim 30$, Hansweert (WS6) halfway the estuary (salinity $\sim 17$ ), Bath (WS10, salinity 11), and one near the Dutch-Belgian Border (Doel, WS11, salinity 7). Data from these sites were retrieved from the database www.waterbase.nl maintained by Rijkswaterstaat (RWS). Chl $a$ and total suspended matter (SPM, mg L ${ }^{-1}$ ) data were obtained from 1978 onwards, although data for 1980 and 1981 are missing for WS1 and WS6. For station Bath (WS10), data were obtained from 1988 to 1995. In addition, the Netherlands Institute of Ecology, Centre for Estuarine and Marine Ecology (NIOO-CEME) has a water quality monitoring program in the same region with 17 stations from Vlissingen in the mouth of the estuary to station Temse (WS17), which is located upstream of Antwerp in the tidal freshwater region. Eleven stations are located in the Dutch part. For station Bath (WS10), we combined data from the RWS database and the NIOO-CEME database, which is not publicly accessible yet. Sampling frequency varied from 11 to 34 times a year and also varied between stations but was in general biweekly apart from the period 1982-1992 when sampling was monthly. In the years 2002-2004, sampling frequency was reduced to monthly in the winter months.

Light data (PAR, $\mu \mathrm{mol}$ photons $\mathrm{m}^{-2} \mathrm{~s}^{-1}$ ) is measured continuously by the NIOO-CEME since 1994 using a LiCor LI190 $2 \pi$ light sensor connected to a LiCor LI1000 datalogger. Hourly averaged data were logged, and total 


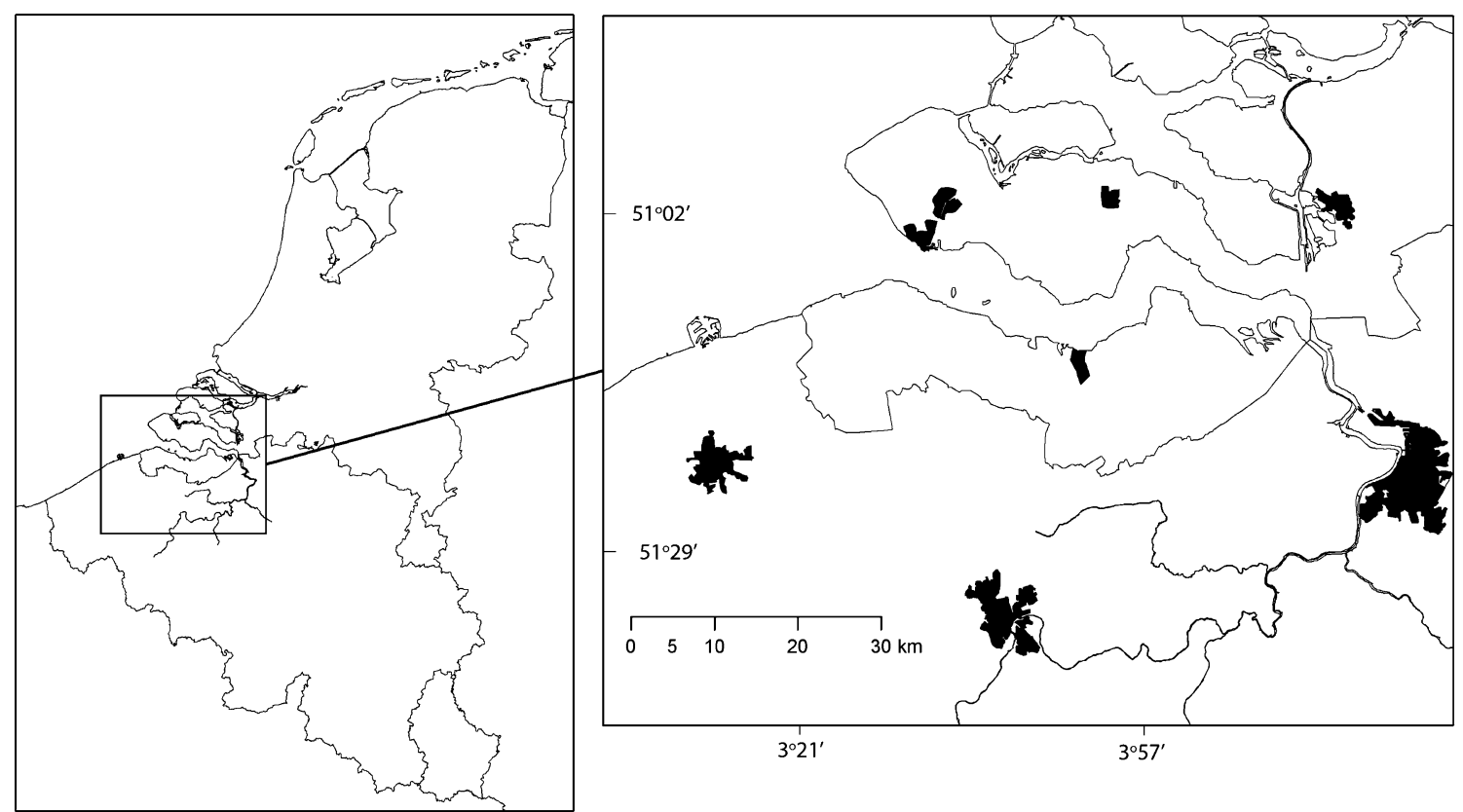

Fig. 1 Study site showing the location of the sampling stations. The letters WS were omitted from the station numbers for reason of clarity. The black areas indicate major cities

daily light was computed ( $\mathrm{mol}$ photons $\mathrm{m}^{-2}$ ). Total daily irradiance data (from $\mathrm{J} \mathrm{cm}^{-2} \mathrm{day}^{-1}$, obtained with a pyranometer) from 1978 to 1994 were obtained from the Royal Netherlands Meteorological Institute from the nearby station Vlissingen. These data were converted to micromole photons per square meter per second by multiplying by a factor $5.5274\left(r^{2}=0.96\right)$ which was based on a comparison of data from $1994(n=365)$.

\section{Phytoplankton Biomass}

Phytoplankton biomass is expressed as chlorophyll $a$ (chla, $\mu \mathrm{g} \mathrm{L}^{-1}$ ) and was extracted in $90 \%$ acetone. In 1986, both the NIOO-CEME and RIKZ changed analyses method from spectrophotometry to reverse-phase HPLC. An analysis of NIOO-CEME data of the 1 year of overlapping techniques demonstrated that this did not influence the estimates of annual mean chla concentrations, although individual samples did show some differences (P. Herman, personal communication). A comparison of the time series from the respective stations did not reveal any systematic changes that could be attributed to changes in the chlorophyll methodology. Particularly strong peaks around 1984-1987 occurred in at least two of the three stations. Wavelet transformations (Maximal Overlap Discrete Wavelet Transform) of the respective time series, which can help in identifying strong sudden changes, demonstrated isolated peaks during this period but no consistent changes throughout the stations (data not shown). This is what one would expect from a methodology-induced shift. In addition, a simple variance analysis of yearly weighted average chla data did not reveal significant differences between the periods 1978-1985 and 1986-2005, corroborating the statement that the methodological change did not affect the results. It should be mentioned that the phenological patterns were not affected at all.

Annual average chlorophyll concentrations were calculated using linear interpolation between the sampling dates and were thus weighted. In general, the weighted mean was close to the arithmetic mean as the sampling interval was quite regular.

\section{Statistical Analyses}

In all time series, a multiyear periodicity appeared to be present. In order to investigate this, we first detrended the WS11 and WS6 data. We did this by fitting a second-order polynomial through the time series $\left(r^{2}=\right.$ 0.85) using the Microsoft Excel trendline fit option and subtracted the fitted data from the actual data. For all stations, we then computed the mean chla concentration for the total period and subtracted this from the actual data at year $t$ and normalized it to the standard deviation of the mean in order to calculate a normalized mean for all stations combined:

$\operatorname{chl} a_{\text {normalized }, t}=\frac{\left[\operatorname{chl} a_{t}\right]-[\overline{\operatorname{chl} a}]}{\operatorname{stdev}[\overline{\operatorname{chl} l a}]}$

Time series were further analyzed using spectral analysis (Fourier transformation) in Statistica 8. In analyzing yearly patterns, we calculated "cumulative" data with time for 


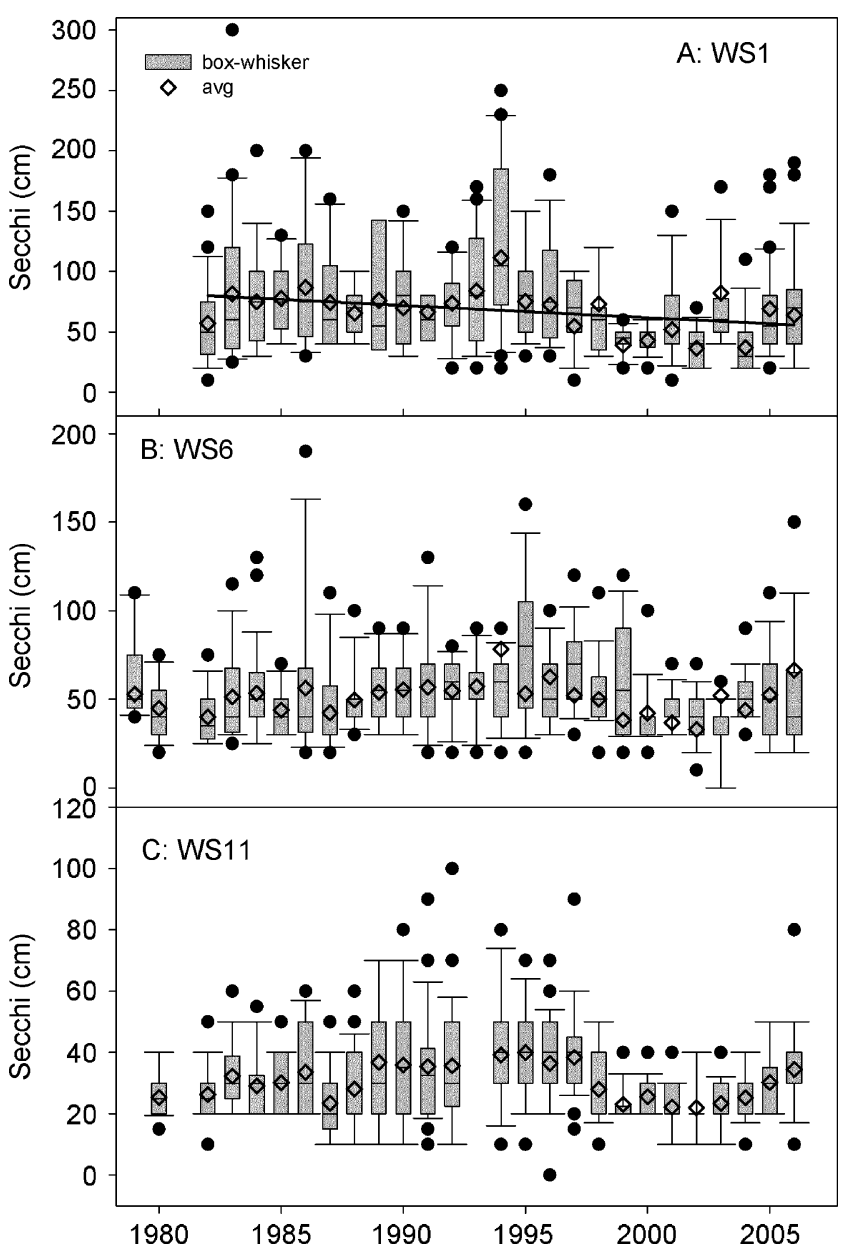

Fig. 2 Secchi depth (cm) at the mouth (WS1), central (WS6), and at the upstream station (WS11). Regression lines are only shown when significant

$\operatorname{chl} a$. These graphs show a clear sigmoidal pattern, and the data were fitted against a three-parameter sigmoidal function in Sigmaplot 9:

$\operatorname{chl} a_{t}=\frac{a}{1+\exp \left(\frac{-t-t_{0}}{b}\right)}$

where $a$ and $b$ are fit constants, and $t$ is the Julian day number. The fits were generally very good $\left(r^{2}>0.99\right)$. From these data, we obtained the day at which $50 \%$ of the total (called the "fulcrum") was reached (see text for further explanation). Plots of this fulcrum date against year were fitted using linear regression in Sigmaplot 9. The advantage of this method over a simple median calculation is the increased sensitivity due to the density fitting.

Changes in the timing of the phytoplankton blooms at stations WS1, WS6, and WS11 were also analyzed with the statistical package R ( $\mathrm{R}$ Development Core Team 2008) using discrete wavelet coherence analysis on monthly averaged data for the period 1982-2005. A wavelet transformation converts the time representation of a series (measurements as function of time) to a time/ scale representation. We used the Maximal Overlap Discrete Wavelet Transformation (MODWT), which essentially gives for each scale a new time series of wavelet coefficients of the same length as the original time series. Each new time series only contains variations at that particular scale. In the case of monthly data, the first wavelet vector will contain all the short-term variations up to 4 months. The second vector groups the 4 - to 8 -month scales, and the third vector presents the 8- to 16 -month scales. The latter also contains the 12-month periodicity (seasonality). The variation is thus filtered and separated into a number of individual scale-specific component signals (scale bands), using so-called wavelet filters. We used the " $k 313$ " Hilbert wavelet filter pair from the Waveslim package (Whitcher 2007) for R (R Development Core Team 2008). This combination is further referred to as a MODHWT, following Whitcher and Craigmile (2004). This MODHWT gives a complexvalued time/scale representation of time series, containing information on the strength (cfr. modulus of a complex number) and phase (cfr. argument of a complex number), similar to the amplitude and phase of, for example, a sine wave. We refer the interested reader to the specialized literature for more technical details (e.g., Percival and Walden 2000; Selesnick 2001, 2002; Whitcher and Craigmile 2005).

In order to investigate the phenology of the phytoplankton bloom, an average seasonality of the chla concentration was obtained by averaging chla values per month of the year. This average seasonal profile was replicated 24 times to obtain a time series of the same length as the original chl $a$ time series. The time-dependent phase difference between the original time series and the replicated annual signal was calculated in a coherence analysis, which is basically a comparison of the MODHWT of the original signal with that of the average seasonal signal. Phenological changes in the chla concentration are detectable as variation in the phase differences between the original time series and the average seasonal chl $a$ signal. Two relevant time scales are obtained; the first describes variability in the scale interval of 4-8 months with a periodicity optimum close to 6 months (second wavelet vector), the second encompasses the variability at scales from 8 to 16 months with a periodicity optimum close to 12 months (third wavelet vector). The time-dependent phase differences in both of these scale bands were averaged per year to eliminate the majority of the interdependence between these values. This allowed for the use of simple regression analysis in assessing the secular trend in these phase differences at each of the scales, without further correction for interdependence of observations. Theoretically, the use of average data might make the data sensitive to extreme 
values. A repeat of the coherence analyses using a median seasonality led to nearly identical seasonal profiles, and there was no difference in significance.

\section{Results}

\section{Seasonal Patterns in Chlorophyll $a$}

From the time series of chla, it can be seen that all stations showed a clear repeatable pattern with a single spring bloom, which occurred later in the season in the upstream stations (Fig. 3). The pattern in the most easterly station (WS11) was more variable. However, the magnitude of the spring bloom varied from year to year, indicating a large variability in average annual chl $a$ concentration. Although difficult to see from these graphs, no long-term trend was visible, with the clear exception of station WS11, which showed a large decrease in phytoplankton biomass that stabilized early in the 1990s. For station WS10, data were only available from 1988 onwards, and this was a combination of data obtained from the database (1988-1995) and CEMELIMS data (1996-2007). No data were available for 1980 and 1981 (WS1 and WS6) and 1987 (WS11).

Interannual Trends in Average Annual Chlorophyll $a$ : Periodicity

In order to investigate if long-term trends were present in phytoplankton biomass, we calculated weighted annual average concentrations (Fig. 4). Large variability was observed from year to year, and a clear decrease in annual chla concentrations was observed for station WS11, i.e., the inland station at the Dutch-Belgian border. Station WS6 showed a decrease with time which was only just significant $(p=0.048)$ at the $5 \%$ level. No long-term change was detected for the most marine-influenced station WS1.

After detrending WS11 and WS6, we plotted the climatologies (anomalies) of chla in Figs. 5 and 6, which were obtained by plotting the difference to the normalized mean of the real data for stations WS1, WS6, and WS10 and the difference of the normalized data to the mean of the normalized data for station 11. Positive values indicated that the actual value was larger than the long-term mean. There appears to be a clear periodicity present in the data in Fig. 5. We first tested this by computing normalized chla concentrations as discussed above, then averaged the normalized data of the different stations and subsequently fitted a sine function through it using the solver function in MS-excel. This resulted in an average periodicity of 7.4 years $\left(r^{2}=0.48\right.$, Fig. 5). To further analyze the individual plots, we performed a spectral analysis on the original average chla concentration for stations WS1 and used the detrended data for station WS11 and WS6 and the normalized averaged data for all stations (Fig. 7). All stations and the average of the normalized data showed a peak in the periodogram at a frequency of 0.143 year $^{-1}$, corresponding to a period of 7 years, and the resulting periodicity confirmed the periodicity of 7.4 years obtained by fitting a sine through the averaged normalized data. The low frequency, corresponding to a period of 28 years for station WS1 was an artifact of the fitting procedure.

\section{Chlorophyll Fulcrum in chla}

To investigate changes phenology we performed two different approaches: we followed the cumulative rise in chlorophyll during the year (Fig. 8) and investigated the month in which the peak of the phytoplankton bloom occurred (Fig. 9). We first describe in which month the maximum chla occurred. This analysis was performed on monthly averaged means as during the period 1982-1992, and sampling was approximately monthly. The results are presented in Fig. 8. Linear regression analyses demonstrated that the earlier occurrence of the blooms in recent years for station WS1 was not significant $(p=0.427)$, whereas the maximum biomass of the phytoplankton bloom was significantly shifted forward in time for stations WS6 (slope is $-0.043 \pm 0.18$ month/year, $p=0.022$ ) and WS11 ( slope $=-0.056 \pm 0.02$ month per year, $p=0.0059$ ). This figure also showed that the maximum of the bloom occurred earlier in WS1 (on average in month4.9) than in WS6 (month 5.5) and WS11 (month 6.2).

Because the time resolution of the monthly averaged means is limited, we further analyzed the data by looking at the chla development throughout the year. We did this by plotting the cumulative chla concentration as a function of time; an example is given in Fig. 9. The graphs showed a clear sigmoidal increase, and by fitting the data with a threeparameter sigmoidal function (see "Statistical Analyses"), from which we could calculate the day at which $50 \%$ of the "annual total" is reached. We called this day the fulcrum, and the analysis is called a fulcrum analysis, which basically is the median of the chla distribution but with an improved time resolution. We plotted the fulcrum data for the period 1978-2006 for stations WS1, WS6, and WS11 in Fig. 10. The results of this plot clearly show that the fulcrum was reached earlier in the year as time progresses. It also was obvious that the fulcrum was reached later in the year at station WS11 than in stations WS1 and WS6. This corroborated the observation above that the height of bloom occurred earlier near the mouth of the estuary than in the more upstream and more turbid brackish region of the estuary. The slopes of the fulcrum analysis were highly significant and showed that the bloom developed earlier by 1 to 2 days/year and that this was most 
Fig. 3 Seasonal dynamics in chla concentrations at stations WS1, WS6, WS10, and WS11.

The inset shows the period 2005 to 2006 in more detail
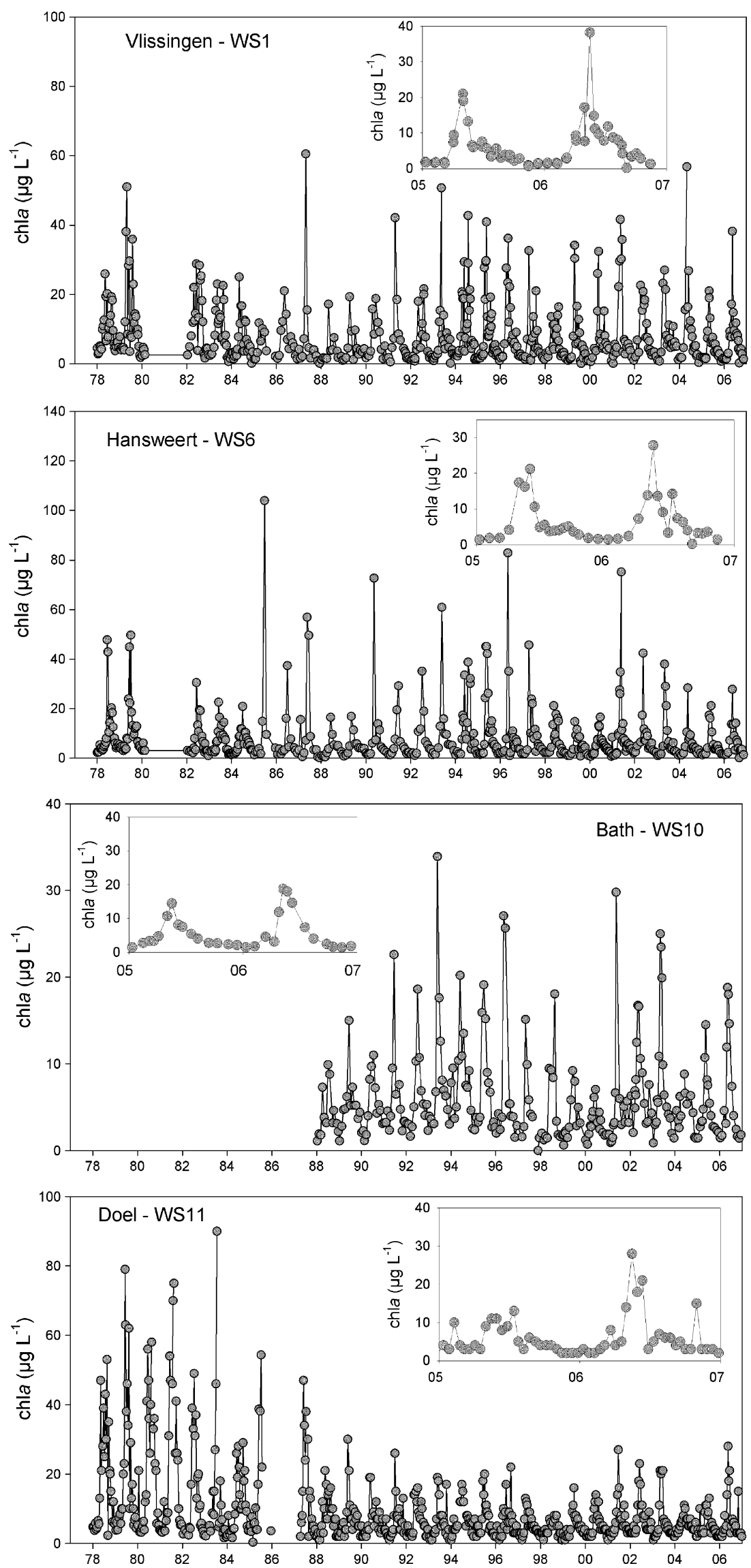

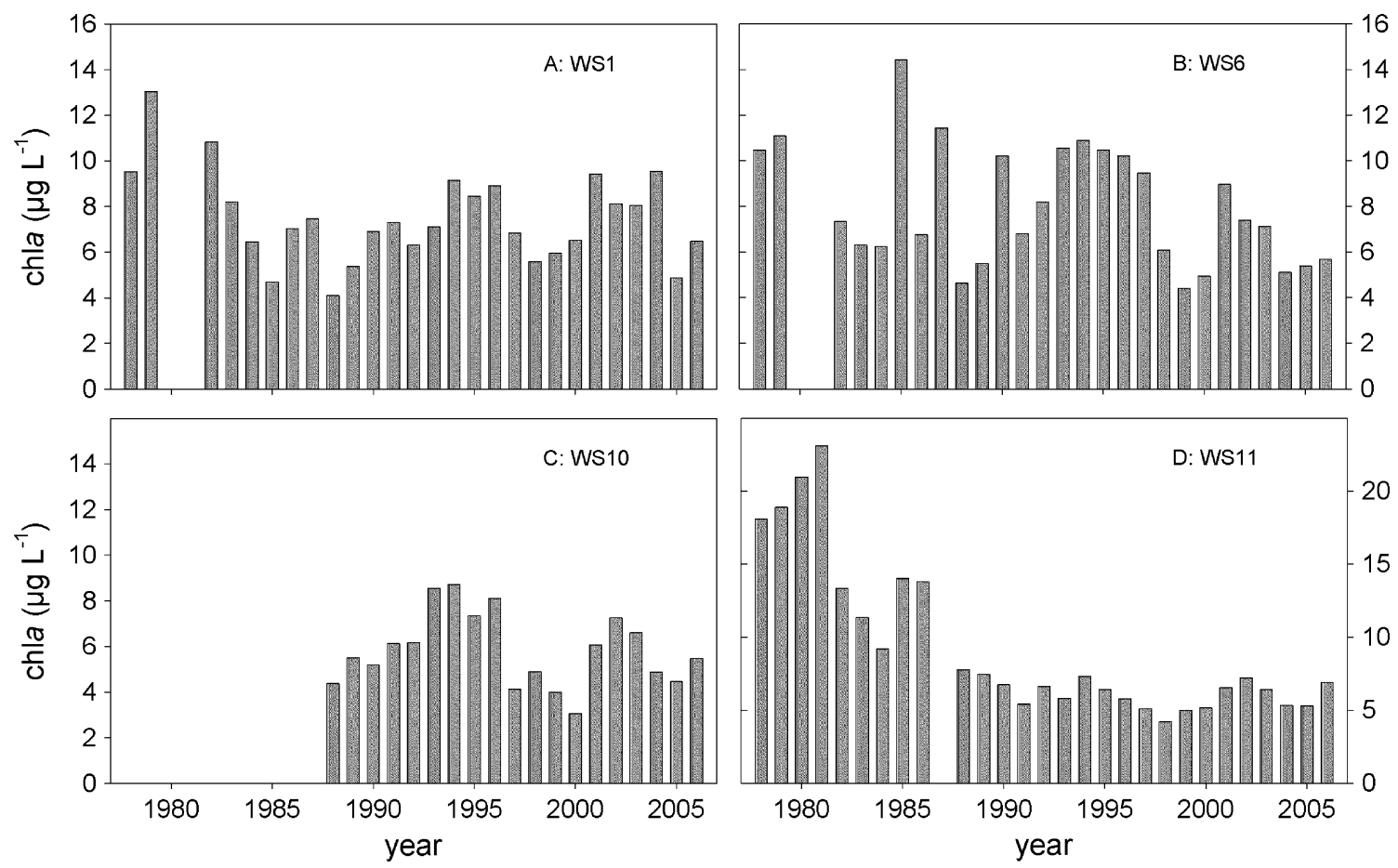

Fig. 4 Annual average chla concentration. Note the different scale for WS11

pronounced for station WS6 (Table 1). A pairwise covariance analyses of the slopes revealed that the slope of WS6 differed significantly from both WS1 $(p=0.035)$ and that WS1 and WS11 were not significantly different
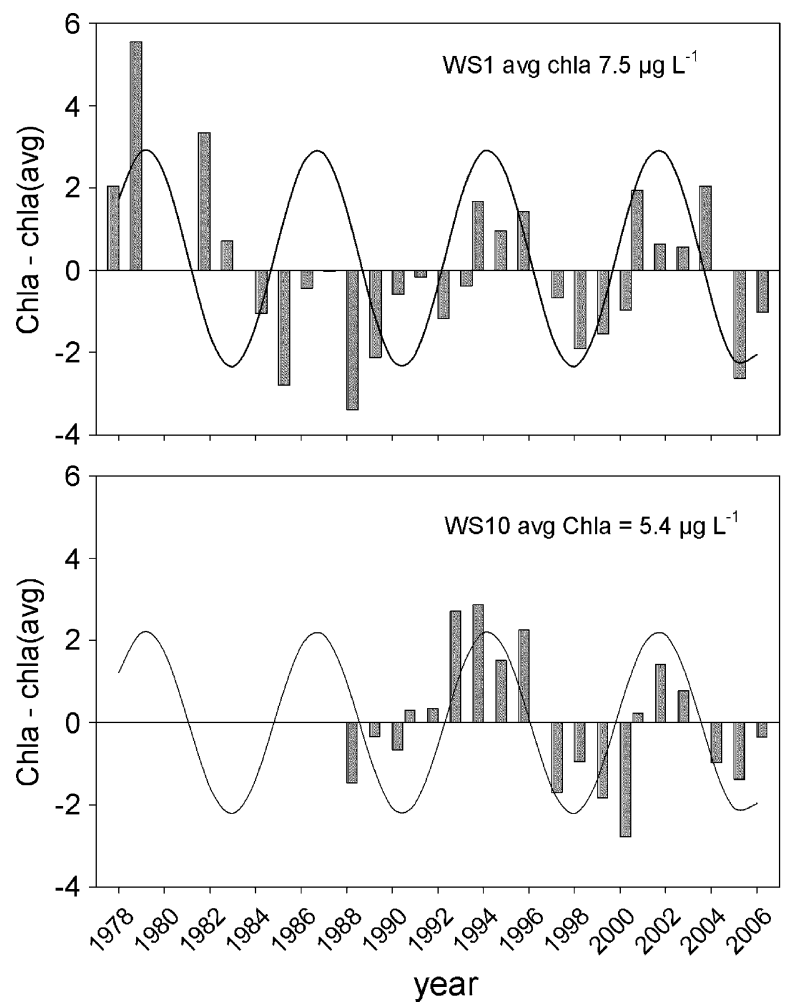

$(p=0.90)$. Interestingly, the earlier occurrence of the bloom for WS1 based on the fulcrum analysis was not supported by the timing of the maximum in the bloom, which did not change during the 30 -year period.
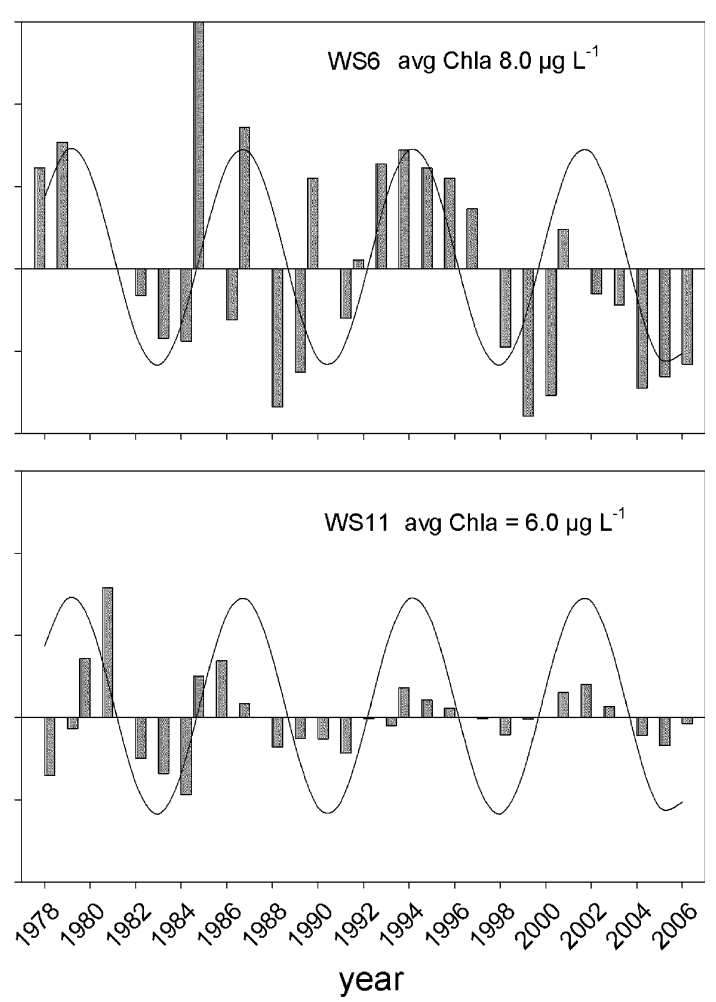

Fig. 5 Climatologies of chla (bars). The line is a sine function which was fitted through the station averaged normalized chla concentrations 
Fig. 6 Climatologies $\left(X-X_{\text {avg }}\right)$ of $\mathbf{a}$ the winter NAO index, $\mathbf{b}$ rainfall (for station WS1), $\mathbf{c}$ river discharge, and $\mathbf{d}$ normalized chla concentrations of station WS1

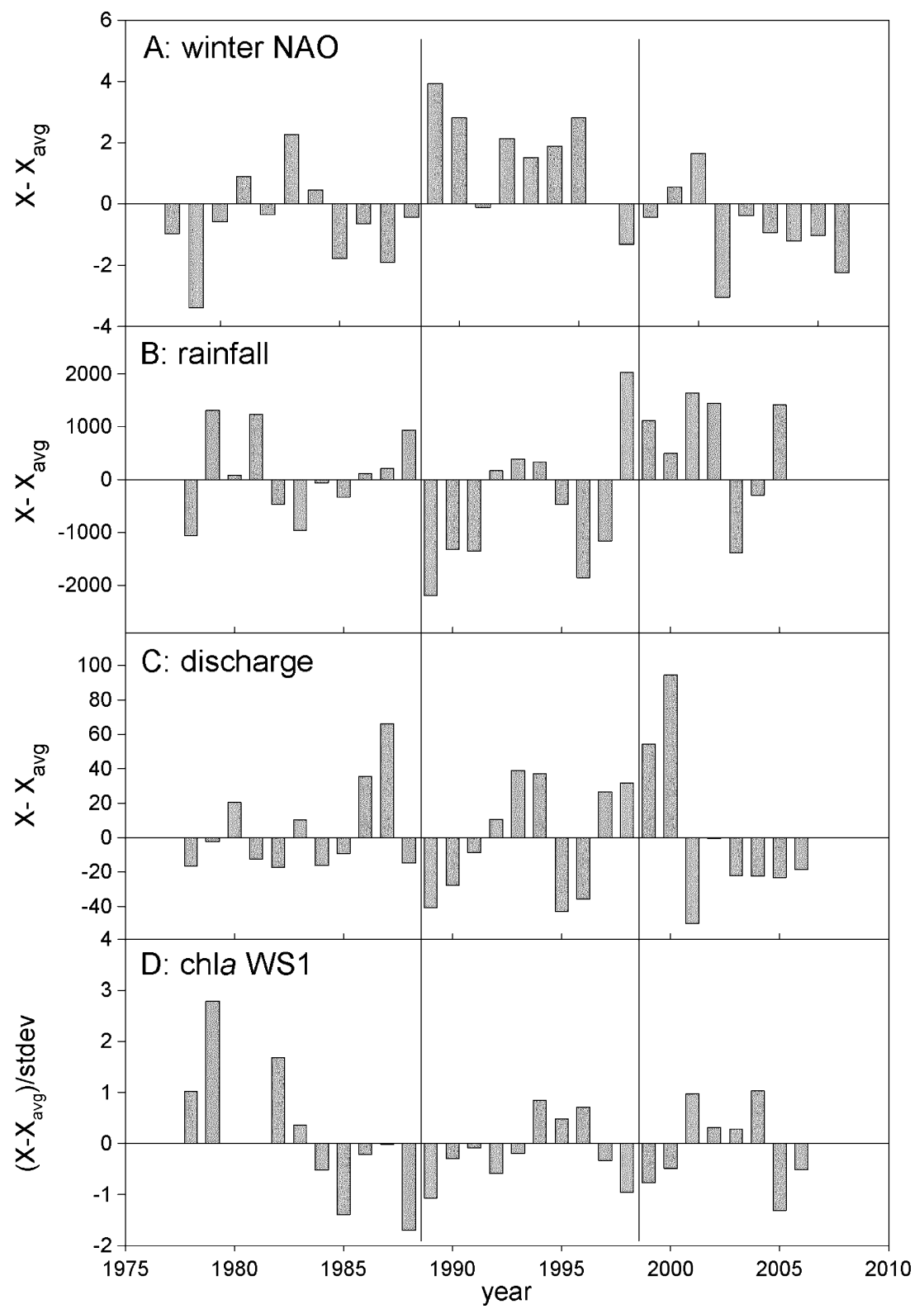

Results Phase Shift Analysis

The differences in phenology between the stations, as mentioned in the previous section, were supported by pairwise coherence (phase) analyses of the WS1, WS6, and WS11 stations. We discuss station WS6 as an example. The result of the other stations can be found in Table 1 . The phase difference at the scale of 4 to 8 months showed a significant positive trend (linear regression, $T=3.859, p=$ 0.001 ), indicating an initial lag of the original series with respect to its average signal (the phase difference is negative). The slope of this time-dependent phase difference was 0.06 radians. If we used the optimum periodicity ( \pm 6 months) of the filter set for this particular scale to convert this phase difference to a time shift, we obtained an average shift of $0.057( \pm 0.015 \mathrm{SE})$ months/year or a total shift over the entire measurement period of $1.367( \pm 0.354$ $\mathrm{SE})$ months. Translated to days, this amounted to an advance of $1.71( \pm 0.45)$ days/year or $41.0( \pm 10.6)$ days between 1982 and 2005 (Table 1). In general, the findings from the phase analyses qualitatively corroborated the results of the fulcrum analyses, except for WS1, which showed a much smaller and no significant change in phenology compared to the fulcrum analysis (Table 1). This was in agreement with the results obtained for the timing of the maximum of the bloom. Quantitative differences were most likely attributable to the fact that the fulcrum analyses focused on a specific point in the distribution, while the phase analyses emphasized an overall temporal shift of the periodic signal in a particular 
Fig. 7 Results of spectral analysis; the periodogram shows a strong maximum at all stations at a frequency of 0.14 years, indicating a periodicity of 7 years. Because it is a discrete analysis, the periods are multiples of complete years. The low frequency in WS1 corresponds to a 28 -year period and is an artifact of the fitting method. The graph labeled "average" shows the result of a spectral analysis on the chla normalized averaged data for stations WS1, WS6, and WS11

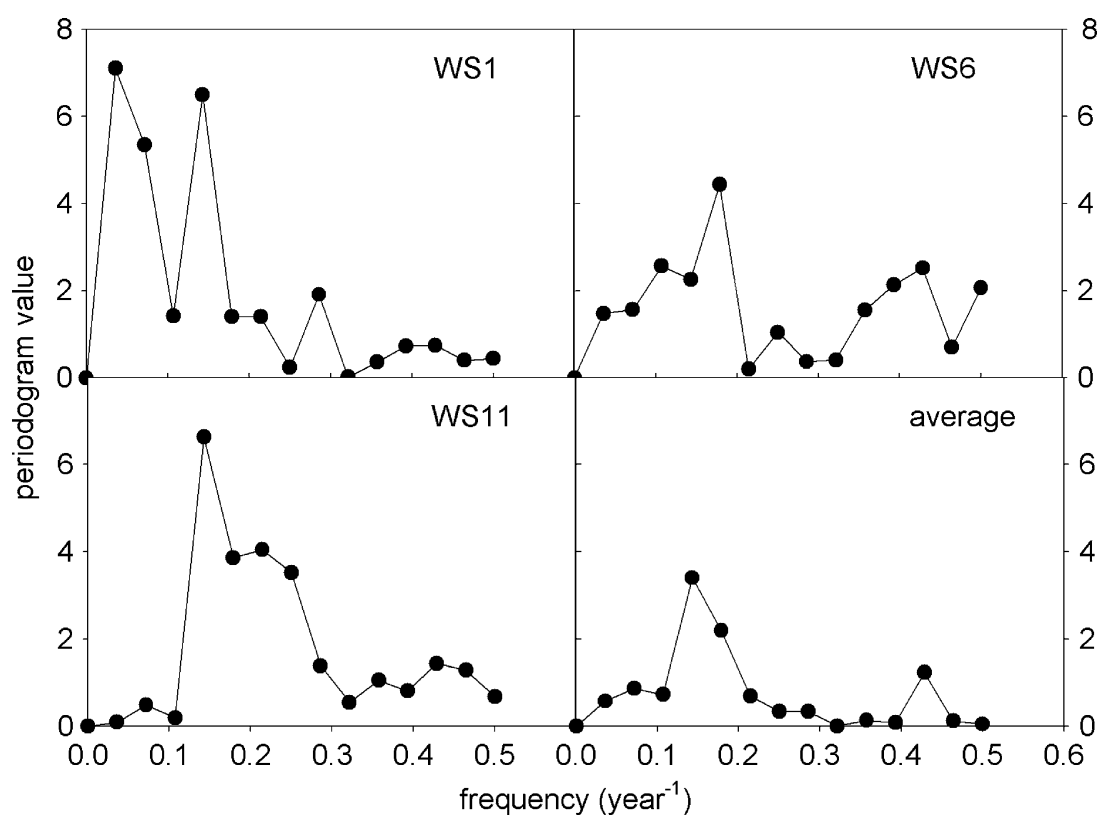

scale band. No specifics were derived concerning the distribution of chla throughout the year from the latter analyses $(20 \%, 50 \%$, and $80 \%$ points, cfr. below).

The deviating result for the phase analysis of WS1 compared to the fulcrum analysis had two potential causes (not mutually exclusive). First, the fulcrum analyses used a more precise time localization in the estimation of fulcrum (to the day), while the wavelet-based analysis was performed using monthly averaged chla values because observations need to be equidistant for these wavelet analyses. The fact that the wavelet analysis did not show a significant phase shift can thus in part be due to a loss of time resolution. This was supported by a nonsignificant

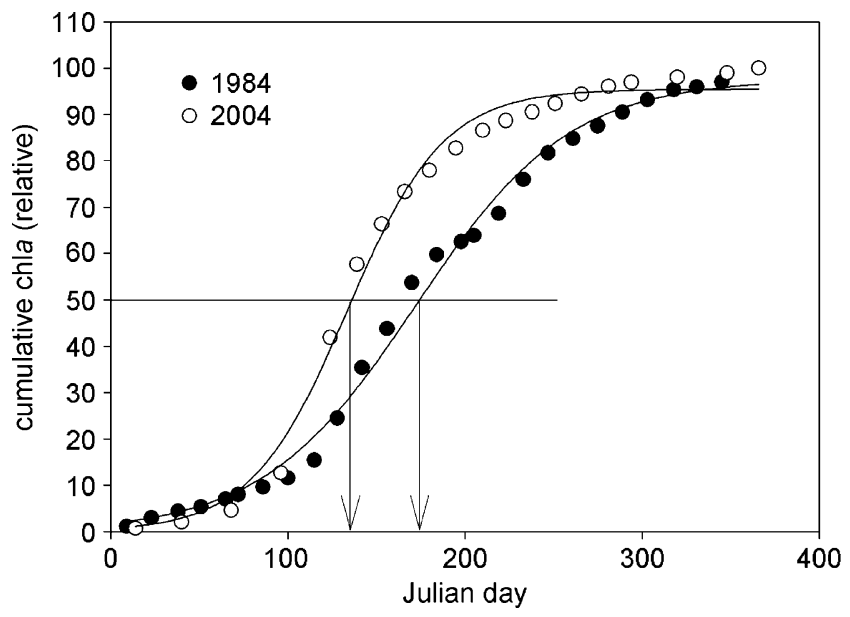

Fig. 8 Examples of a fulcrum analysis showing the relative cumulative chla concentrations as a function of the day of the year for 1994 and 2004. The day when $50 \%$ of the total is reached (the fulcrum) is indicated by an arrow. These examples were some of the poorer fits result from a fulcrum analysis on monthly averaged chla concentrations. Secondly, the fulcrum analysis is more sensitive to increases in the annual maximum concentration. This was tested using an artificially constructed time series, consisting of the average annual profile of the WS1 signal, but with a linearly increasing maximum of the

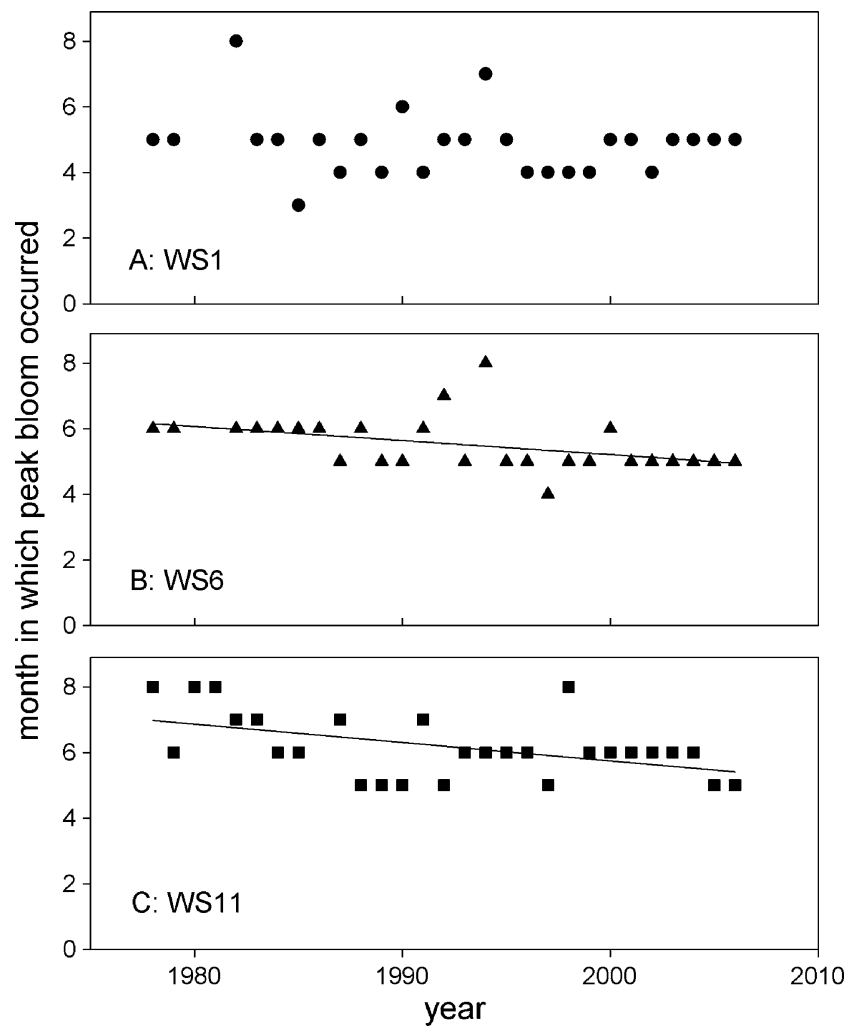

Fig. 9 Month in which the maximum phytoplankton biomass (chla) was observed. Regression lines are only shown when significant 


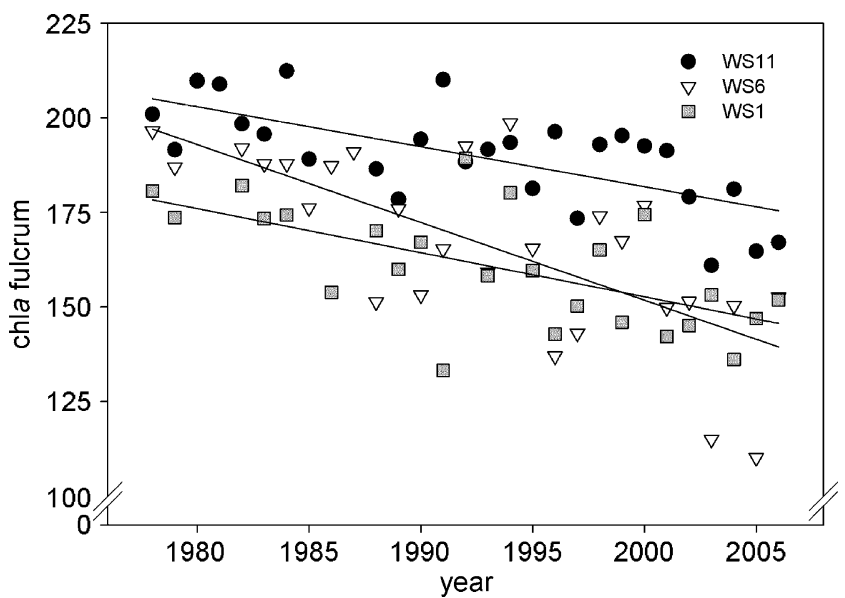

Fig. 10 Results of the fulcrum analysis performed on yearly development in chla. All three stations clearly show that the fulcrum is reached earlier in the year in recent years

bloom peak similar to that found in the original series. The fulcrum advanced linearly over time with an increasing bloom maximum, which means that, with an increasing bloom maxima, the fulcrum can advance without any real change in phenology. However, the sensitivity for this process was too small to explain the significant advance of the fulcrum for WS1.

Phytoplankton Bloom Initiation, Termination, and Bloom Length

The sigmoidal rise in cumulative chl $a$ can also be used to analyze the length of the bloom period. From Fig. 9, it can be concluded that the bloom coincided with the steep part of the curve, which was approximately delineated by the days during which the plot reached $20 \%$ and $80 \%$ of the

Table 1 Statistics of the fulcrum and wavelet analyses on changes in chlorophyll $a$

\begin{tabular}{|c|c|c|c|c|c|}
\hline & & Slope & Slope error & $p$ & $r^{2}$ \\
\hline \multicolumn{6}{|c|}{ From sigmoidal fits } \\
\hline \multicolumn{2}{|l|}{ WS1 } & -1.1663 & 0.2792 & 0.0004 & 0.38 \\
\hline \multicolumn{2}{|l|}{ WS6 } & -2.0571 & 0.4072 & $<0.0001$ & 0.51 \\
\hline \multicolumn{2}{|l|}{ WS11 } & -1.0568 & 0.2220 & $<0.0001$ & 0.48 \\
\hline \multicolumn{6}{|c|}{ From wavelet analysis } \\
\hline \multirow[t]{2}{*}{ WS1 } & Bloom & -0.032 & 0.353 & 0.930 & $<0.01$ \\
\hline & Season & 0.381 & 0.470 & 0.381 & 0.029 \\
\hline \multirow[t]{2}{*}{ WS6 } & Bloom & 1.709 & 0.443 & 0.001 & 0.40 \\
\hline & Season & 1.242 & 0.443 & 0.010 & 0.26 \\
\hline \multirow[t]{2}{*}{ WS11 } & Bloom & 0.845 & 0.460 & 0.080 & 0.13 \\
\hline & Season & 1.538 & 0.424 & 0.002 & 0.37 \\
\hline
\end{tabular}

Bloom means the timing of the peak in biomass, and season refers to the whole bloom period

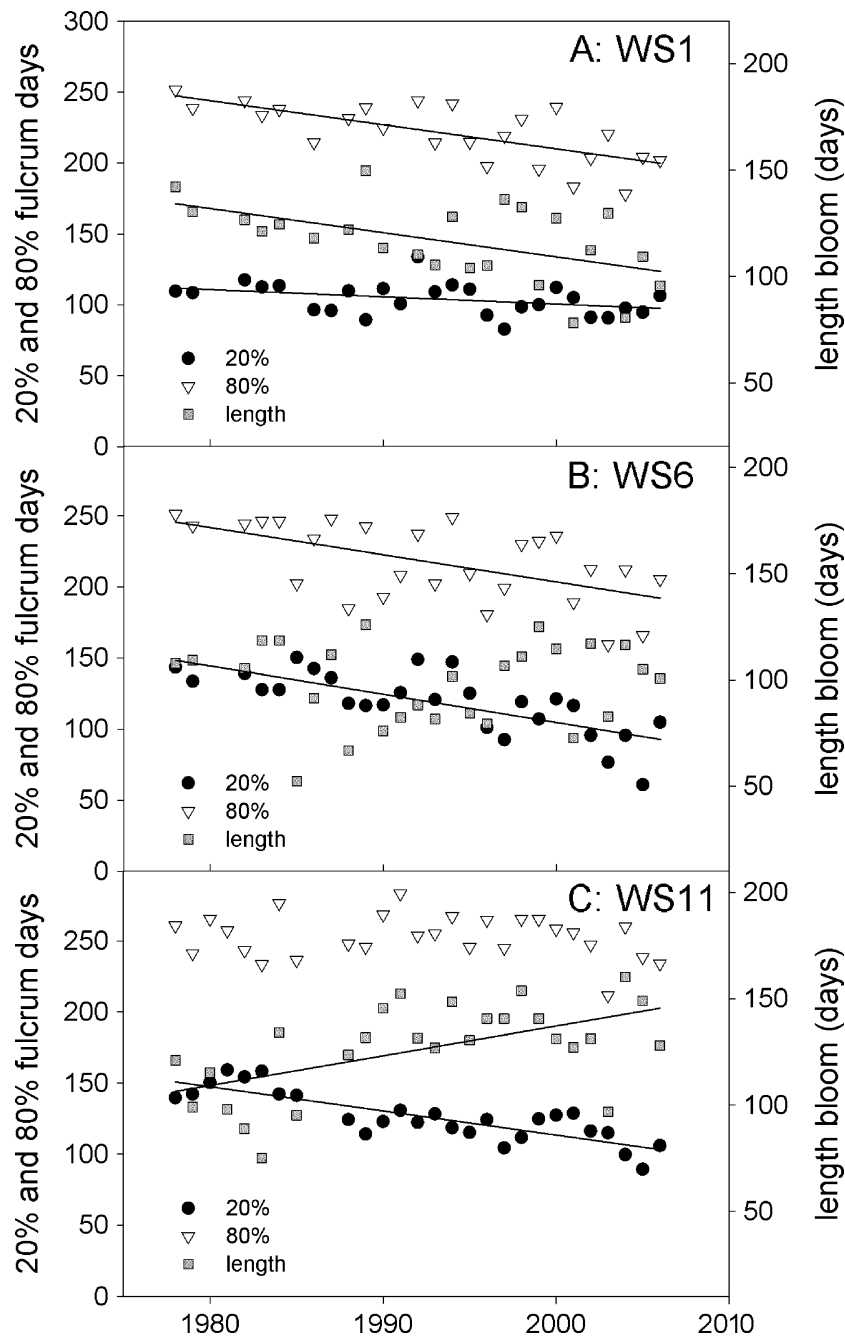

Fig. 11 Analysis of the length of the bloom. The start of the bloom is defined as day when $20 \%$ of the total cumulative chla concentration is reached, and the termination day of the bloom is when $80 \%$ is reached. The length of the bloom is the number of days between the $20 \%$ and the $80 \%$ day. Regression lines are only shown when significant

cumulative biomass, respectively. From the logistic fit parameters, we calculated when these days occurred for every year, and from this, we calculated the length of the bloom period as the day at which $80 \%$ was reached minus the day at which $20 \%$ of the cumulative chl $a$ was reached (Fig. 11). For stations WS1, we see that the bloom initiation started a little earlier in more recent times ( $\sim 0.5$ days/year), but the change was small but significant (Table 2). The end of the bloom, however, occurred clearly earlier in the year (1.7 days/year). As a result, the length of the bloom was shortened from approximately 134 days in 1978 to 106 days in 2006. It was mainly due to the earlier termination of the bloom that the fulcrum occurred earlier in the year in more recent times. 
Table 2 Statistics of the secular trends in bloom initiation (defined as the day when the cumulative chla reached $20 \%$ of the total), bloom termination (day at which $80 \%$ of the chla is reached), and the length of the bloom

\begin{tabular}{lllrl}
\hline Parameter & Slope & Slope error & \multicolumn{1}{l}{$p$} & $r^{2}$ \\
\hline WS1-20\% & -0.5118 & 0.2311 & 0.0366 & 0.145 \\
WS1-80\% & -1.702 & 0.331 & $<0.0001$ & 0.492 \\
WS1 length & -1.139 & 0.3432 & 0.0031 & 0.287 \\
WS6-20\% & -1.9869 & 0.3362 & $<0.0001$ & 0.546 \\
WS6-80\% & -1.9064 & 0.5006 & 0.0008 & 0.3328 \\
WS6 length & 0.0805 & 0.4372 & 0.8554 & 0.001 \\
WS11-20\% & -1.7017 & 0.2223 & $<0.0001$ & 0.694 \\
WS11-80\% & -0.3056 & 0.3405 & 0.378 & 0.032 \\
WS11 length & 1.3961 & 0.4098 & 0.0022 & 0.31 \\
\hline
\end{tabular}

The situation for station WS6 was different. Here, both the time when the bloom started and when it ended occur earlier in the year, and as a result, the length of the bloom did not change and lasted about 100 days, which was significantly shorter than the bloom at station WS1.

Again, station WS11 showed a different pattern. As in the other stations, the initiation of the bloom occurred earlier in the year, but the termination date of the bloom phase did not change significantly (Table 2). As a result, there was a significant increase in the length of the bloom. Thus, the situation at station WS11 was opposite to those in WS1, and station WS6 exhibited an intermediate pattern. Interestingly, the periodicity observed in the annual chla concentrations was also visible in the bloom initiation data. Spectral analyses revealed a clear periodicity with a period of 9.3 years for stations WS1 and WS11 and a periodicity of 7 years for WS6.
Suspended Matter, Secchi Depth, and Temperature

Light was probably the most important factor determining algal growth rates. Nutrients most likely did not play a role because they are generally thought to be in excess (Kromkamp and Peene 2005; Soetaert et al. 2006), although low phosphate concentrations have been observed for short periods in most marine stations of the Western Scheldt estuary (Table 3). From Fig. 2, it is clear that Secchi depth was the shallowest at station WS11 and deeper at station WS1, which corroborated the fact that blooms occurred earlier at WS1 than at WS6, followed by WS11. To determine if light availability might have played a role in the secular changes or apparent periodicity, we investigated possible changes in total suspended matter, incident irradiance, and Secchi depth. No long-term trend in SPM was observed for station WS1: regression analyses showed that the observed positive trend was not significant (analysis of variance (ANOVA), $p=0.15$, Fig. 12). Annual variability was considerable with highest SPM concentrations observed in 1991 and 2002. Station WS11 near the Dutch-Belgian border showed a decrease in average annual SPM concentrations (ANOVA, $p=0.039$ ). Secchi depth $\left(z_{\mathrm{S}}\right)$ was another measure of light availability and in principle more directly related to light attenuation than SPM, but the number of observations for SPM was much higher than those for $z_{\mathrm{S}}$ (mainly for station WS1). The deepest Secchi depths were observed in the marine part of the estuary and the shallowest in the upstream part of the Western Scheldt, which corresponds to the fact that the lowest SPM concentrations were observed in station WS1 and the highest at station WS11 (Fig. 12). The increase in SPM observed for station WS1 was corroborated by the decrease in Secchi depth (ANOVA, $p=0.033$ ). Stations WS6 and WS11 did not show a significant trend, although substantially higher visibility was observed between 1989 and
Table 3 Average, minimum, and maximum nutrient concentrations $(\mu \mathrm{M})$ for stations WS1 and WS11 for the periods 1978-1980 and 2004-2006

\begin{tabular}{|c|c|c|c|c|c|c|}
\hline \multirow[t]{2}{*}{ Station } & \multicolumn{3}{|l|}{ WS1 } & \multicolumn{3}{|l|}{ WS11 } \\
\hline & Average & Minimum & Maximum & Average & Minimum & Maximum \\
\hline \multicolumn{7}{|c|}{ 1978-1980 } \\
\hline $\mathrm{PO}_{4}{ }^{3-}$ & 3.7 & 1.7 & 5.8 & 17.7 & 7.8 & 27.5 \\
\hline $\mathrm{NH}_{4}^{+}$ & 15.1 & 2.1 & 52.9 & nd & nd & nd \\
\hline $\mathrm{NO}_{3}$ & 62.8 & 13.6 & 124.3 & 239.1 & 36.5 & 365.7 \\
\hline $\mathrm{SiO}_{4}$ & 19.4 & 0.7 & 49.9 & 162.4 & 57.0 & 263.5 \\
\hline \multicolumn{7}{|c|}{ 2004-2006 } \\
\hline $\mathrm{PO}_{4}{ }^{3-}$ & 1.6 & 0.2 & 2.5 & 4.6 & 2.9 & 6.3 \\
\hline $\mathrm{NH}_{4}^{+}$ & 3.6 & 0.1 & 10.2 & 14.6 & 0.1 & 82.4 \\
\hline $\mathrm{NO}_{3}$ & 44.2 & 14.4 & 88.6 & 287.0 & 170.6 & 394.9 \\
\hline $\mathrm{SiO}_{4}$ & 17.3 & 1.0 & 42.0 & 95.3 & 20.3 & 168.5 \\
\hline
\end{tabular}



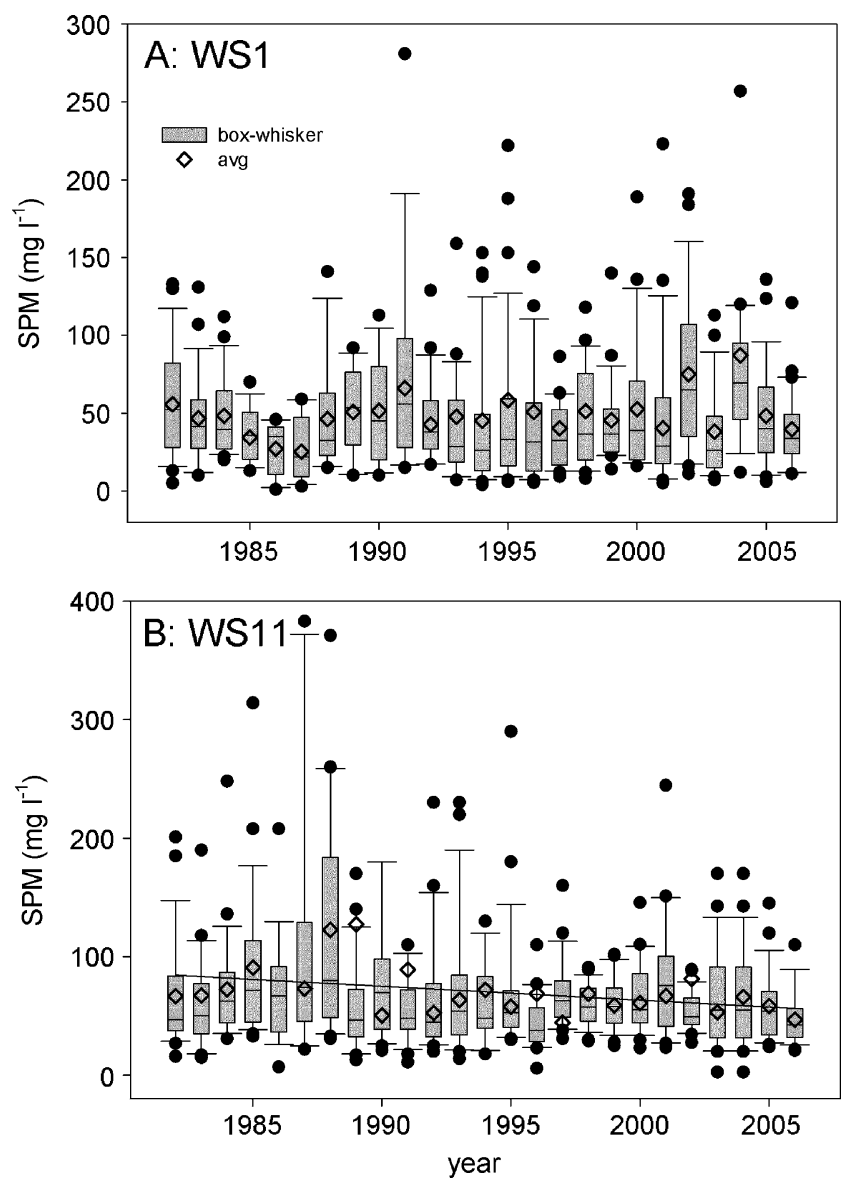

Fig. 12 Box plots of changes in SPM at a station WS1 and b WS11 in the Western Scheldt estuary. Regression lines are only shown when significant. The box encloses the 25th to 75 th percentiles and the line in the box marks the median. The whiskers (error bars) indicate the 10th and 90th percentiles. The dots are outside this range

1997 at station WS11. Although interannual fluctuations were observed in SPM, there was no obvious periodicity and thus no relationship with the interannual changes in chl $a$ (data not shown).

We also looked at differences in incident irradiance $\left(E_{\mathrm{o}}\right)$. No significant secular trend was observed in the yearly average irradiance nor in the average irradiance during the spring period (April-May). We also investigated the timing of the maximum in annual irradiance in a fulcrum analysis (data not shown). As might be expected, the fulcrum was very constant and occurred on 23 June \pm 3 days. The day at which $20 \%$ of the cumulative irradiance was reached was only slightly more variable, 21 April \pm 4 days. A Fourier analysis revealed no clear periodicity in the yearly variations in both the average in April-May or $E_{\mathrm{o}}$ (data not shown).

Detailed temperature records are presented in Fig. 13. In contrast to most of the variables above, temperature showed a clear increase during the nearly 28 -year period which we investigated. Although the yearly fluctuations were large and varied from year to year, the overall rise in the annual

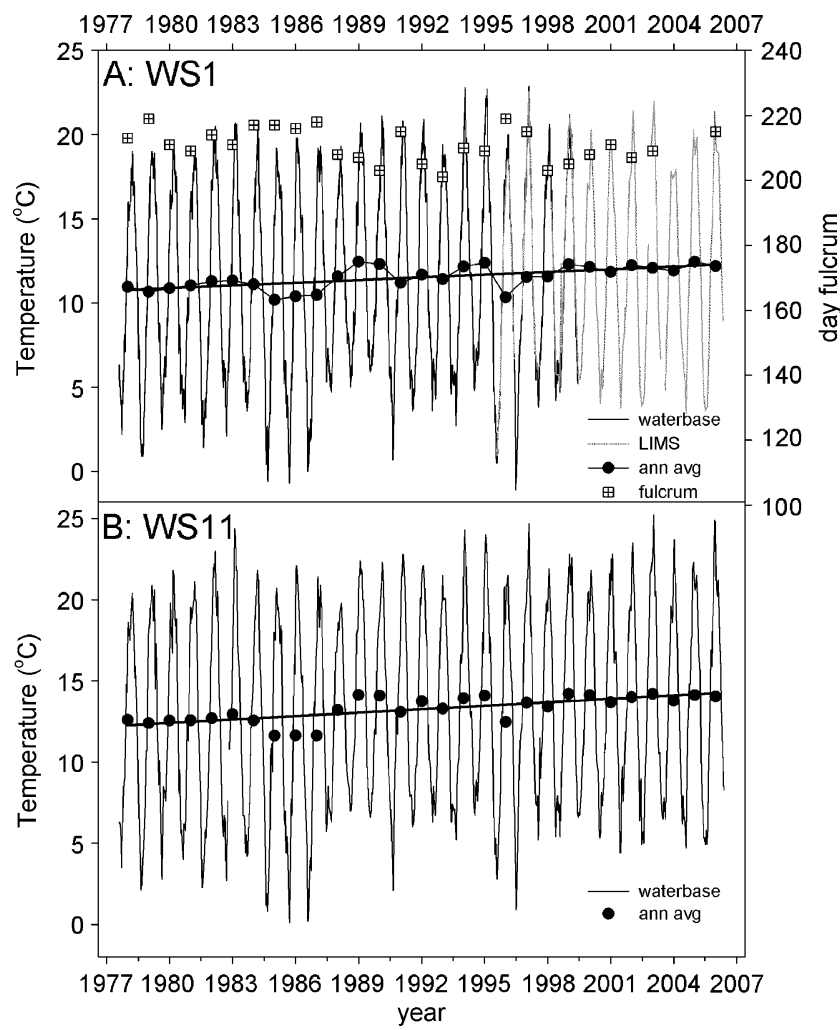

Fig. 13 Changes in temperature at stations a WS1 and b WS11. The day of the fulcrum is given for WS1 only. The annual average is shown as filled circles. Regression lines are only shown when significant. Data are from the water-base and CEME-LIMS data bases

average was $0.053^{\circ} \mathrm{C} /$ year for station WS1 and $0.0706^{\circ} \mathrm{C} /$ year for station WS11, and both results were highly significant $(p=0.0001)$. We also performed a fulcrum analysis on the temperature data (WS1 only). No significant trend was observed in the fulcrum, demonstrating that the warming was more or less evenly distributed throughout the year.

\section{Discussion}

We analyzed interannual variation in chla concentration of Western Scheldt phytoplankton, and as expected, a large variability in interannual chla was obtained. It is rather difficult to assess whether this variability was real or was partly due to methodological sampling issues. During the 30year period, sampling frequency varied from 11 to 34 samplings per year with approximately biweekly sampling apart from a 10-year period between 1982 and 1992 and some monthly sampling in the period 2002-2004. When we realize that phytoplankton doubling rates will probably vary between 0.5 and 4 days, depending on the season and resource conditions, monthly sampling intervals will likely lead to under-sampling, but this sampling interval is nevertheless quite common. This can be clearly seen in Fig. 14, where we 

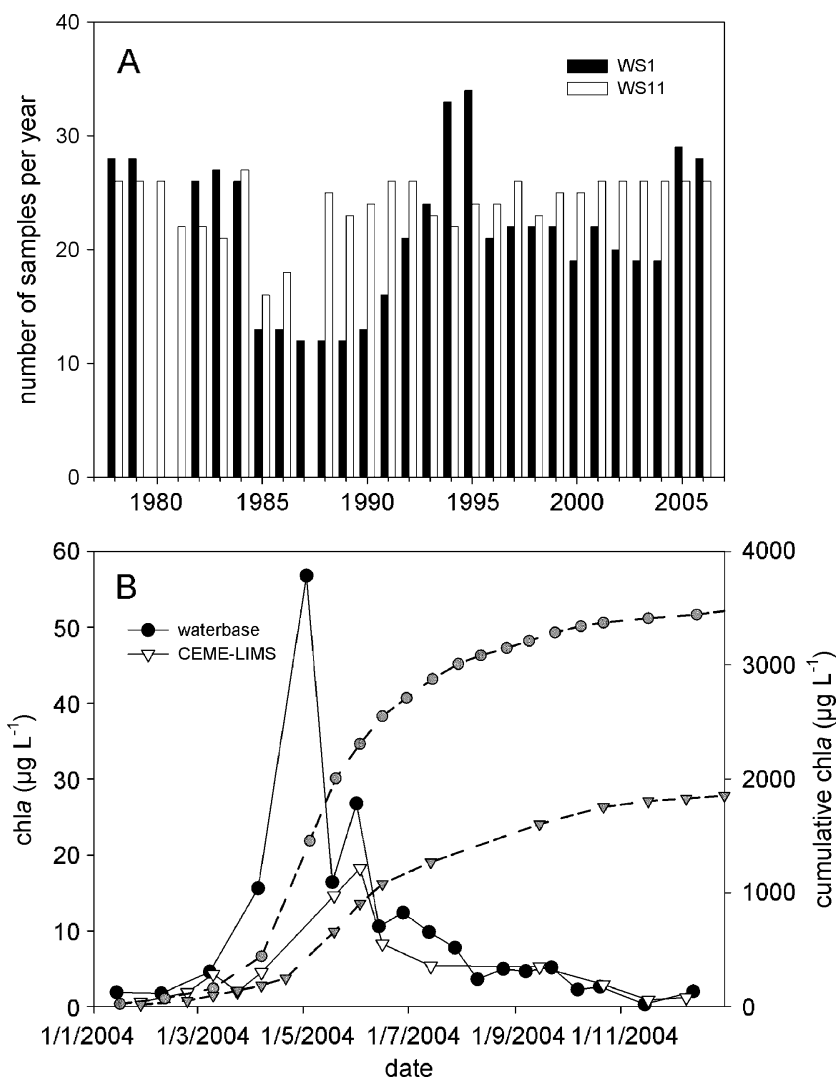

Fig 14 a Number of samples per year (black and white bars), and $\mathbf{b}$ comparison between the chla concentrations (filled circles and open triangles) and cumulative chla (gray circles and triangles) for data obtained from the water-base (circles) and the CEME (inverted triangles) databases

compare the chla concentrations in 2004 obtained by the RIKZ monitoring program with that of the NIOO-CEME: Due to less frequent sampling by the NIOO-CEME (12 sampling points in 2004; Fig. 14), it missed the spring phytoplankton bloom in early May which was observed by the RIKZ sampling effort (19 sampling points in 2004). As a result of missing this event during the bloom by the NIOOCEME (one sampling point!), the calculated average annual chla concentration was approximately $50 \%$ lower than the estimate based on the water-base data! Although this was the worst comparison that we could detect, this example stresses the importance of sampling at the right interval, at least during the periods of the year when the major blooms occur.

\section{Interannual Variability in Phytoplankton Biomass}

Two main time scales were observed showing variability, one with a period of 12 months and one with a period of about 7 years. Of course, the former one is the time scale describing the spring or summer bloom which clearly showed one single peak each year. A smaller second autumn bloom, often presented in many marine systems, was sometimes observed, and it was often more pronounced in the primary production data (Kromkamp and Peene 1995a). The initiation of the spring bloom was earlier in the marine stations, exemplified by station WS1, where the light conditions were better than in the more turbid inner stations where the spring bloom moved toward a single summer bloom (e.g., WS11). It is hard to explain the individual difference in the magnitude of the bloom. It may be limited by nutrients (not very likely, but it cannot be ruled out for the recent years for station 1), but the fact that there was no overall trend in chla concentrations suggested that nutrient limitation did not play a prominent role. Blooms might also be terminated by grazing, settling/ sinking, viral infections, or periods with low solar irradiance, and since no information about most of these factors is available, it is not very fruitful to speculate further.

More interesting is the reason behind the apparent periodic behavior. All stations showed a 7-year periodicity in the average annual chla concentration according to the spectral Fourier analysis. Periodicity was also observed in the onset of the bloom, although the time scales did not exactly match for stations WS1 and WS11 but did match for station WS6, and the climatologies were also approximately synchronous. Large El Niño events were observed in 1982-1983 and 1997-1998, and during these occasions, we observed that the chla climatologies switched from positive to negative, suggesting teleconnections to the atmosphere. The Scheldt estuary is a rain-fed river, and rainfall and river discharge might thus be important drivers for the phytoplankton. As rainfall is influenced by the North Atlantic Oscillation (the pressure difference between Iceland and the Azores), we might expect a relationship between the NAO, rainfall, and river discharge. In 1988, the NAO index increased to the highest values that have been observed thus far this century (Reid et al. 2001), causing large-scale changes in the hydrodynamic regime and a rise in temperature. It is thought to be the driving force behind the observed regime shift in the North Sea (Beaugrand 2004b; Beaugrand and Ibanez 2004; deYoung et al. 2004; Weijerman et al. 2005) and Baltic Sea (Beaugrand 2004b). We calculated the average value of the NAO index for the period 1978-2006 and compared these NAO deviations from the average (climatologies) to the deviations in annual rainfall (measured at station WS1), discharge (measured near station WS11), and the annual chla of station WS1 (Fig. 13). Generally, it appears that when the rainfall is higher than the 1978-2006 average, then the NAO index is smaller than the mean for this period (Fig. 6). This is unexpected because a positive NAO coincides with more rainfall in North Western Europe and more severe dry periods in Southern Europe. Despite the low $r^{2}$ of 0.15 for the regression analyses, the relationship was significant (ANOVA, $p=0.036$ ). No relationship was found between 
the NAO and annual river discharge or annual chla. Interestingly, a time series analysis on the average annual data revealed a strong 7-year periodicity for both rainfall and river discharge, the same frequency as was observed for the periodic interannual variation in chla.

Another reason for the observed interannual variability with a quasi 7 year period in chla concentrations might be the variation in light availability, temperature, or nutrient concentrations. However, no significant relationship could be detected with incident irradiance, with the average incident irradiance in April-May (the period of the start of the spring bloom) or with Secchi depth. No periodicity was observed in phosphate concentrations. Also, there was no relationship between the fluctuation in temperature and chla concentrations. Thus, it seems reasonable to suggest that interannual changes in rainfall leading to varying rates of discharge are the drivers behind the 7-year periodic behavior in phytoplankton biomass in the Scheldt estuary.

\section{Shifts in the Timing of Bloom Characteristics}

Secular trends were observed in the bloom characteristics. All three stations for which we have a 30-year record in chl $a$ concentrations showed that the fulcrum (i.e., the day at which $50 \%$ of the cumulative chla distribution was reached) moved forward with time at a rate of 1-2 days/ year. These changes were highly significant and thus resulted in a shift in 1 to 2 months during this period! The results were corroborated by the time series analysis which investigated which month the phytoplankton bloom reached its maximum by wavelet analysis. Only station WS1 showed a complex result, and this was mainly due to the higher sensitivity of the fulcrum analysis to higher spring peak concentrations compared to the wavelet coherence analysis.

Further analyses of the bloom dynamics showed a complicated pattern. The onset of the bloom (defined as the day when the cumulative chl $a$ concentrations reached $20 \%$ ) showed the blooms started earlier with approximately 0.5 day/year for station WS1 and nearly 2 days/year for stations WS6 and WS11. The termination of the bloom showed a different pattern. In both stations WS1 and WS6, the bloom terminated earlier at a rate of 1.7-1.9 days/year. Station WS11 showed no significant change in the time of the bloom termination. As a result, the length of the bloom decreased by $\sim 1$ day/year for station WS1 (i.e., the sigmoidal rise in cumulative chla became steeper). In station WS6, the bloom started and ended earlier at about the same rate, leaving the bloom length unchanged. Station WS11 again showed a different pattern. Because the bloom started earlier but did not change its termination date, the length of the bloom actually increased by 1.4 days/year. These different patterns in bloom dynamics demonstrate the complex nature of estuarine ecosystems and how difficult it is to predict changes accurately.

How can we explain these secular trends in the timing of the different bloom events? In a turbid eutrophic estuary like the Western Scheldt, two main bottom-up factors can probably explain an earlier initiation of the bloom, an increase in the light climate, or an increase in temperature. The former one would allow the day the critical depth is exceeded to move to an earlier date, whereas the latter one would stimulate the growth rate, although the effect of temperature on light-limited growth rate is very limited (Post et al. 1985). A vertical stabilization of the water column is one way to improve the light climate, but it does not play a role in the well-mixed macro-tidal Western Scheldt estuary. No long-term trends were observed in incident irradiance. With respect to light availability for phytoplankton growth, we conclude that the underwater light climate at station WS1 hardly changed. For station WS11, we observed a significant decrease in SPM, suggesting a decrease in turbidity. However, this was not corroborated by the Secchi disk data. Whether this discrepancy is due to noise or to the fact that there was a significant change in colored dissolved organic matter (CDOM), which does influence Secchi depth but not SPM, remains to be resolved. Our time series of CDOM started in 2004, and hence, it is too short to draw conclusions, although we observed a clear increase during these few years. Therefore, following Sverdrups' critical depth hypothesis (Sverdrup 1953), we would not expect an earlier start of the bloom at stations WS1 and WS6. Other studies also did not reveal an earlier phytoplankton spring bloom, which mainly consists of diatoms (Edwards and Richardson 2004; Wiltshire et al. 2008), and it has been suggested that this might be related to the fact that germination of diatoms resting spores is related to photoperiod length (Eilertsen et al. 1995) and that this might explain the consistency in the timing of the spring bloom observed in other studies. Hence, our results for stations WS1, WS6, and perhaps WS11 clearly did not follow this pattern.

The observed earlier occurrence in the bloom initiation and the fulcrum fit may be linked to global warming. Phenological trends in terrestrial ecosystems have clearly shown an earlier development of plant growth and an increase in the length of the growing season as a result of global warming. We also did observe a significant rise in temperature at both WS1 and WS11 (Fig. 13), suggesting a temperature rise in the whole estuary with a rate of about $0.05-0.07^{\circ} \mathrm{C} /$ year. This is higher than the $0.043^{\circ} \mathrm{C}$ found near Helgoland (German Bight, North Sea) for the same period (Wiltshire et al. 2008) or for the western English Channel or the Bay of Biscay in the 1980-2000 period (Hawkins et al. 2003). Increased temperatures might have 
promoted higher winter phytoplankton stocks, but this was not observed, as the winter concentrations of chla in WS1 or WS6 did not change significantly (data not shown). This was of course not the case for station WS11, which showed an overall decrease in chla concentrations which also exhibited a decrease in winter concentrations due to the regime shift, and is a result of the improved oxygen conditions allowing grazers to enter the upstream part of the estuary (Appeltans et al. 2003). Despite these conditions, an earlier start of the season and an earlier date of the fulcrum were observed as well at this station. Our result deviated from those observed in the coastal North Sea by McQuatters-Gollop et al. (2007), who observed that a combination of sea surface temperature and winter and Secchi depth was the best predictor for the chla concentration and that, as a result, the chla concentrations in both the coastal and open North Sea increased after 1980.

The earlier termination of the bloom observed in WS1 and WS6 can be due to several factors. Nutrient depletion might play a role, but we think this is very unlikely in this eutrophic estuary where nutrients are in excess. Also, if nutrient reduction played a role, it might have reduced the overall productivity of the phytoplankton, but as the average yearly chla concentrations did not change significantly for stations WS1 and WS6, this was unlikely to have played a role. In addition, the phosphate concentrations at station WS1, the most likely station to be limiting, did not decrease after 1995 .

In summary, we obtained evidence for a cyclic pattern in the annual mean chla concentrations which we could attribute to varying discharge rates. We observed in all stations that the day at which $50 \%$ of the annual cumulative chl $a$ was reached occurred earlier in the season. No significant trend was observed in the annual mean chla concentrations for stations WS1 and WS6, but chla concentrations for WS11 decreased due to improved oxygen conditions, allowing important pelagic grazers to have access to the upstream part of the estuary. All stations also showed an earlier initiation of the phytoplankton bloom, although the earlier shift was very limited for station WS1. The phytoplankton bloom also showed an earlier termination of the bloom, apart from station WS11, which did not show a change in the termination date. As a result, the length of the bloom decreased in WS1, remained the same for station WS6, and increased for station WS11. This demonstrates the complex nature of estuarine ecosystem functions. The earlier shifts in time coincided with a rise in temperature, showing an expected change in phenology, i.e., in the timing of the phytoplankton blooms.

Acknowledgments We would like to thank the EU-program EUROCEANS for sponsoring JCK's visit to the AGU Chapman conference on long-term time series observations in coastal ecosystems in Rovinj,
Croatia, which started this analysis. Thanks are due to Jim Cloern and Alan Jassby for providing us with stimulating ideas. We would also like to thank two anonymous reviewers for their helpful comments. This is NIOO publication 4604.

Open Access This article is distributed under the terms of the Creative Commons Attribution Noncommercial License which permits any noncommercial use, distribution, and reproduction in any medium, provided the original author(s) and source are credited.

\section{References}

Appeltans, W.A., S. Hannouti, K. Van Damme, R. Soetaert, vanthomme, and M. Tackx. 2003. Zooplankton in the Schelde estuary (Belgium, The Netherlands). The distribution of Eurytemora affinis: Effect of oxygen? J Plankton Res 25: 1441-1445.

Beaugrand, G. 2004a. Monitoring marine plankton ecosystems. I: Description of an ecosystem approach based on plankton indicators. Marine Ecology Progress Series 269: 69-81.

Beaugrand, G. 2004b. The North Sea regime shift: Evidence, causes, mechanisms and consequences. Progress in Oceanography 60: $245-262$.

Beaugrand, G. and F. Ibanez. 2004. Monitoring marine plankton ecosystems. II: Long-term changes in North Sea calanoid copepods in relation to hydro-climatic variability. Marine Ecology Progress Series 284: 35-47.

Chiba, S., M.N. Aita, K. Tadokoro, T. Saino, H. Sugisaki, and K. Nakata. 2008. From climate regime shifts to lower-trophic level phenology: Synthesis of recent progress in retrospective studies of the western North Pacific. Progress in Oceanography 77: 112126.

Cloern, J.E. 2001. Our evolving conceptual model of the coastal eutrophication problem. Marine Ecology Progress Series 210: 223-253.

deYoung, B., R. Harris, J. Alheit, G. Beaugrand, N. Mantua, and L. Shannon. 2004. Detecting regime shifts in the ocean: Data considerations. Progress in Oceanography 60: 143-164.

Edwards, M., G. Beaugrand, P.C. Reid, A.A. Rowden, and M.B. Jones. 2002. Ocean climate anomalies and the ecology of the North Sea. Marine Ecology Progress Series 239: 1-10.

Edwards, M. and A.J. Richardson. 2004. Impact of climate change on marine pelagic phenology and trophic mismatch. Nature 430: 881-884.

Eilertsen, H.C., S. Sandberg, and H. Tollefsen. 1995. Photoperiodic control of diatom spore growth-A theory to explain the onset of phytoplankton blooms. Marine Ecology Progress Series 116: 303-307.

Hakanson, L. and D. Lindgren. 2008. On regime shifts and budgets for nutrients in the open Baltic Proper: Evaluations based on extensive data between 1974 and 2005. J Coastal Res 24: 246-260.

Hare, S.R. and N.J. Mantua. 2000. Empirical evidence for North Pacific regime shifts in 1977 and 1989. Progress in Oceanography 47: 103-145.

Hawkins, S.J., A.J. Southward, and M.J. Genner. 2003. Detection of environmental change in a marine ecosystem-Evidence from the western English Channel. Science of the Total Environment 310: $245-256$.

Kromkamp, J. and J. Peene. 1995a. On the net growth of phytoplankton in two Dutch estuaries. Water Science and Technology 32: 55-58.

Kromkamp, J. and J. Peene. 1995b. Possibility of net phytoplankton primary production in the turbid Schelde Estuary (SW Netherlands). Marine Ecology Progress Series 121: 249-259. 
Kromkamp, J.C. and J. Peene. 2005. Changes in phytoplankton biomass and primary production between 1991 and 2001 in The Westerschelde Estuary (Belgium/The Netherlands). Hydrobiologia 540: 117-126.

McQuatters-Gollop, A., D.E. Raitsos, M. Edwards, Y. Pradhan, L.D. Mee, S.J. Lavender, and M.J. Attrill. 2007. A long-term chlorophyll data set reveals regime shift in North Sea phytoplankton biomass unconnected to nutrient trends. Limnology and Oceanography 52: 635-648.

Percival, D.B. and A.T. Walden. 2000. Wavelet methods for time series analysis. Cambridge: Cambridge University Press.

Post, A., R. de Wit, and L. Mur. 1985. Interaction between temperature and light intensity on growth and photosynthesis of the cyanobacterium Oscillatoria agardhii. J Plankton Res 7: 487-495.

R Development Core Team (2008). R: A language and environment for statistical computing. R Foundation for Statistical Computing, Vienna, Austria. ISBN 3-900051-07-0, URL http:/www.Rproject.org.

Reid, P.C., MdF Borges, and E. Svendsen. 2001. A regime shift in the North Sea circa 1988 linked to changes in the North Sea horse mackerel fishery. Fisheries Research 50: 163-171.

Scheffer, M., D. Straile, E.H. van Nes, and H. Hosper. 2001. Climatic warming causes regime shifts in lake food webs. Limnology and Oceanography 46: 1780-1783.

Selesnick, I.W. 2001. Hilbert transform pairs of wavelet bases. IEEE Signal Processing Letters 8(6): 170-173.
Selesnick, I.W. 2002. The design of approximate Hilbert transform pairs of wavelet bases. IEEE Trans on Signal Processing 50(5): 1144-1152.

Soetaert, K. and P.M.J. Herman. 1995. Estimating estuarine residence times in the Westerschelde (the Netherlands) using a box model with fixed dispersion coefficients. Hydrobiologia 311: 215-224.

Soetaert, K., J.J. Middelburg, C. Heip, P. Meire, S. Van Damme, and T. Maris. 2006. Long-term change in dissolved inorganic nutrients in the heterotrophic Scheldt estuary (Belgium, The Netherlands). Limnology and Oceanography 51: 409-423.

Sverdrup, H.U. 1953. On conditions for the vernal blooming of phytoplankton. J Cons int Explor Mer 18: 287-295.

Walther, G.R., E. Post, P. Convey, A. Menzel, C. Parmesan, T.J.C. Beebee, J.M. Fromentin, O. Hoegh-Guldberg, and F. Bairlein. 2002. Ecological responses to recent climate change. Nature 416: 389-395.

Weijerman, M., H. Lindeboom, and A.F. Zuur. 2005. Regime shifts in marine ecosystems of the North Sea and Wadden Sea. Marine Ecology Progress Series 298: 21-39.

Whitcher, B. (2007). Waveslim: Basic wavelet routines for one-, twoand three-dimensional signal processing. $\mathrm{R}$ package version 1.6.1.

Whitcher, B. and P.F. Craigmile. 2004. Multivariate spectral analysis using Hilbert wavelet pairs. International Journal of Wavelets Multiresolution and Information Processing 2(4): 567-587.

Wiltshire, K.H., A.M. Malzahn, K. Wirtz, W. Greve, S. Janisch, P. Mangelsdorf, B.F.J. Manly, and M. Boersma. 2008. Resilience of North Sea phytoplankton spring bloom dynamics: An analysis of long-term data at Helgoland Roads. Limnology and Oceanography 53: 1294-1302. 